\title{
PRAEFATIO IOANNIS VAHLENI
}

Carolum Lachmınnum notım est extremis vitae annis, tum cum totus erat in restituendo Lueretio, simul Lueilii saturarum versus superstites emendate scriptos edere constituisse: qua in re quantum hoe felix acumen profecisset, eum speciminibus quibusdam per prooeniorum academicorum occasionem editis tum magis ipso illo conmentario in Lucretium composito patefactum erat. Itaque cum anno mocccli immatura mors virum incomparabilem his studiis ac litteris nostris eripuisset mox rumor pererebuit, Lucilianarum reliquiarum $\sigma v \lambda \lambda o \gamma \dot{\eta} v$ paene absolutam in scriniis eius inventam eamque a Mauricio Hauptio, quo nemo propius ad Lachmanni ingenium ac familiaritatem accesserat, propedien editum iri: eique rumori Martinus Hertzius fidem addiderat in vita Lachmanni p. 149 s. et xxvir n. Sed expectationi doctorum valde erectae, quippe quibus nilil gratius acceptiusve accidere potuisset quam hoc extremo Lachmanni opere 
frui, multos annos Hauptius non respondit, ac paulatim haec spes omnis aliquando reclusum iri hune thesaurum ut vana abiecta est. Verum Hauptio ipso mense Februario anni mbccclxxiv acerba morte absumpto cum amici eius consilium inirent edendi si qua edenda reliquisset, protractae sunt cum aliis chartae Lucilianae suscitatumque est illud iam consopitum Lucilii Lachmanniani desiderium. Itaque cum ego auctumno anni MDcccLxxıv Berolinum venissem, provinciam Hauptii obitu vacuam factam aditurus, Theodorus Mommsenus, Hauptii et Lachmanni dum in vivis erant familiaris idemque mihi favens et cupiens, mecum de edendi libelli cura suscipienda egit: et ego inspectis quae parata erant cum et posse haec edi et editum iri cum magno litterarum emolumento mihi persuasissem, accepi condicionem tantumque exinde huic officio operae impendi quantum nultis distento negotiis in hac novitate rerum licuit.

Barata autem offendi haec, primum Lachmanni schedas, nitidissime scriptas, in summo margine saturarum libri notam scriptam tenentes cui quodque fragmentum attribui iuberet testimonium aut ratio suaderet, indicia quoque nonnumquam propiorem cognationem si qua erat inter versus duos aut plures significantia, dein versus ipsos, emendatos aut quae emendari posse desperarat uncinata, denique testium verba et adnotationem editoris, haec ita inter se discreta uti nunc discreta leguntur. Accedebat earundem schedarum apographon Hauptii manu et subtili diligentia factum; quod is operis traditurus erat: notulas adiecerat quibus typothetam regere solemus, praefixerat indicem, eundem 
qui nune legitur, praeter annum, quem ille posuerat, MDc.cLII, quae in praefatione memorare vellet adnotaverat haec 'ubi necessarium videbatur comm. in Luer. commemoravi': tam fervide tamque certus rei protinus perficiendae aliquamdiu hoc edendi consilium agitaverat, dein nescio qua causa omissum, nec umquam postea uti videtur resumptum. Praeterea praesto fuit Hauptii exemplar Lucilii Gerlachiani, in cuius marginibus cum alia ad hanc rem pertinentia tum coniecturas quasdam suas adnotaverat velut v. 678 tete abstuleris et versuum $152-159$ distributionem scripturamque eam, quae nune e Lachmanni schedis editur: sed praecipue eo usus erat exemplo ad explorandum ecquinam Lucilii versus in Lachmanni schedis non apparerent, apparentibus in illo libro lineola notatis, additurus ipse si quid a Lachmanno reliquum factum constaret.

Verum apographon illud cum non per omnes Lachmanni schedas pertineret sed complecteretur tantum versus singulis libris adscriptos et incertorum hac inscriptione facta $i-x x v$. xxx' versus $986-1020$, hoc primum meum erat, reliqua ex Lachmanni schedis adiicere: atque incerta haec non metro sed libro fragmenta bifariam disposui ita, ut versus dactylicos eodem indice continuaren illis quos Hauptium iam exarasse dixi, trochaicos autem et iambicos hac inscriptione 'xxvi-xxvin' comprehensos libro xxvin subiicerem. Sed hexametri illi cum non omnes unius generis partim sine libri numero tradantur partim signati numero sed falso, item iambici et trochaici versus a grammaticis aut nulla libri nota aut prava designentur, Lach- 
mannus numero non vero insignitis versibus verum quem putaret adscripsit aut certe traditum verum non esse significavit, reliquos auten ita divisit ut dactylicorum parti alteri ' $\mathrm{I}-\mathbf{x x v}^{\mathrm{s}}$ ', alteri et maiori quidem parti ' $1-\mathbf{x x v}$. xxx' adfigeret, trochaicis autem et iambicis pro metrorum genere vel 'xxvir. xxix' adscriberet vel 'xxvi-xxix', rationes seilicet secutus eas, quas in altero illorum prooemio exposuit, quae nune cum ceteris eius opusculis in peculiari libello simul cum Lucilio prodeunte legi possunt. His igitur, quae ad Lachmanni mentem declarandam momentum facere apparet, usus sum ita, ut fragmentis ad hunc modum ordinatis indicia illa omnia sicut in schedis praescripta erant testium verbis sed uneis inclusa adnecterem.

Sed in certorum quoque librorum fragmentis a se digestis Hauptius nonnulla aut in versibus aut testimoniis aut in titrisque inchoaverat tantum non perseripserat, sive quid ipse Lachmannus ineertum reliquerat sive deerat omnino schedula Lachmauni, alibi nulla littera seripta sed spatio vacuo relieto significarat esse quae in retractando apographo addere vellet. Haec ego perseripsi et addidi ea lege nilil ut ipse emendarem sed poëtae verba et grammaticorum testimonia ita ponerem ut ante vulgari solebant, et illis quidem fragmentis quae sine Lachmanni scheda inchoaverat tamen Hauptius, asteriscos praefixi, quibus ipsum in eis quae a se addita essent usum viderem, quae vero non ducente Hauptio in spatiis ab co relictis adieci, ea ut meo unius consilio nitentia extra numeros versuum posui, neminem ut decipere possent. Ad eundemque modum disposui et exaravi ea quae in 
incertis desiderari videbam a Gellio maxime Macrobioque relata fragmenta: nee tamen ut omnia asciscerem quac poteram, sed ut relinquerem prinum ea, quae ne potuisse quidem Lachmannum ipsun aut Hauptium illo anno erlere intellegrebam, dein olim vulgata, quae aut perperam essent ad Lucilium relata aut illos viros inter huius poëtac reliquias.edituros fuisse certa dubitatio esset. Quipue non hoc nune agendun erat, ut quam plenissima haee Lucilianorum collectio extaret, sed ut quantum fieri posset talis exiret qualem aut Lachmamns aut proxime post Lachmanni obitum Hauptius editurus fuisse videretur. Quae etsi est sane manca, tamen tantam partem ab jpso esse Laclımamo adornatamı apparet, ut non rerendun sit, ne hac administrata editione inutilem rem gessisse videamur: verum ita sentimus, magni viri operam etiam non ad umbilicum alductam et diu pressam nee suo tempore editam non obsolescere sed uli primum prodeat lucem spargere inexpectatam et veri appetentibus gratam.

Scrib. Berolini m. Septembri a. moccclux. 
